This journal is the official publication of Bangladesh Society of Physiologists (BSP)

Web URL: www.banglajol.info/index.php/JBSP

Abstracted/indexed in Index Copernicus, Director of Open Access Journal, HINARI Index Medicus for South East Asia Region, Google Scholar, 12OR, infobse index, Open J gate, Cite factor, Scientific indexing services

pISSN-1983-1213; e-ISSN-2219-7508

\title{
Article
}

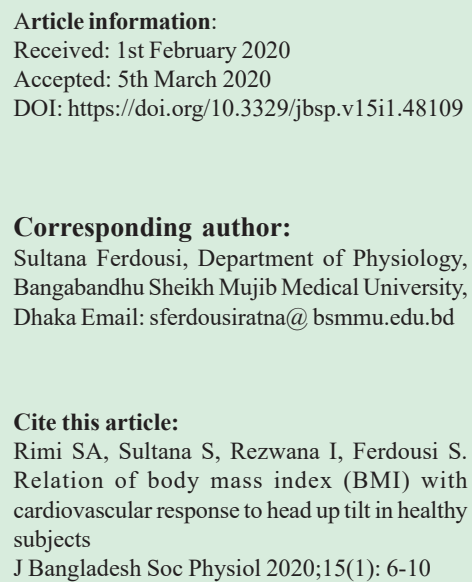

This article is open access licensed under CC BY NC SA which allows readers copy, distribute, display, and perform the work and make derivative works based on it only for noncommercial purposes.

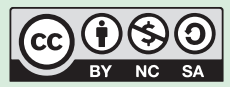

\section{Relation of body mass index (BMI) with cardiovascular response to head up tilt in healthy subjects}

\author{
Sadia Afrin Rimi ${ }^{1}$, Shamima Sultana ${ }^{1}$, Iffat Rezwana ${ }^{1}$, \\ Sultana Ferdousi ${ }^{1}$ \\ 1. Department of Physiology, Bangabandhu Sheikh Mujib Medical University, \\ Dhaka

\section{Abstract}

Background: Tilt table test is used for the last few decades to detect cause in unexplained syncope. The response to tilting may vary physiologically with obesity. Objective: To assess the relationship of BMI to cardiovascular response to tilting. Methods: This experimental study was conducted from March 2019 to Feb 2020 on 90 healthy subjects with different BMI. Fifty one subjects of both gender with BMI 18.5-24.9 kg/m² were included in the non-obese group and 39 subjects of both gender with BMI of $25-29.9 \mathrm{~kg} / \mathrm{m}^{2}$ were included in overweight group and they were further subdivided into male and female. Head up tilting was done for 10 minutes at $60^{\circ}$ by using a motorized tilt table. Systolic blood pressure (SBP), diastolic blood pressure (DBP) were recorded by an automatic sphygmomanometer. Heart rate (HR) and peripheral capillary oxygen saturation $\left(\mathrm{SpO}_{2}\right)$ were measured by a pulse oximeter. For statistical analysis, Independent sample ' $t$ ' test, Pearson's correlation test and Chi square tests were applied. Results: Significantly smaller rise of heart rate was observed in overweight males and greater fall of systolic blood pressure was observed in overweight females. Conclusion: This study concluded that over weight is associated with reduced orthostatic tolerance to head up tilt test in both genders.

Key words: BMI, Over weight, tilt test, HR, Fall of SBP

Volume 15 No. 1 June 2020: 6-10 
Introduction

$\mathbf{O}$ besity is the major global public health problem. Its prevalence and dramatic rise have adverse impacts on health and well being of the people. For the last four decades, obesity is intensely increasing in developed countries. ${ }^{1-2}$ According to the WHO standard, BMI range $25-29.9 \mathrm{Kg} / \mathrm{m}^{2}$ is considered overweight. ${ }^{3-4}$

The association of autonomic impairment with obesity is well recognized. Impaired sympathetic and parasympathetic response in tilting and reduced baroreceptor sensitivity (BRS) was observed in obese person. ${ }^{1,5-7}$ Tilt table test is a "gold standard" useful noninvasive technique that has been used for the last few decades to observe the human body's response to various stimuli for assessment of autonomic nerve function. ${ }^{8}$ The response of the tilt test may vary physiologically with BMI in healthy subjects. Though tilt response on obesity was investigated but information about the relationship of BMI to tilt response is lacking. Moreover, tilt response in overweight subjects had yet not been reported. Therefore, this study has been designed to evaluate the effect of tilting on BMI on apparently healthy subjects.

Methods

This experimental study was carried out from March 2019 to February, 2020 at the Department of Physiology, BSMMU, Shahbag, Dhaka. Ninety (90) apparently healthy subjects of 1860 years of both gender and whose BMI was ranged $18.5-29.9 \mathrm{~kg} / \mathrm{m}^{2}$ and were enrolled by purposive sampling. Subjects were selected from personal contacts, relatives, attendants of patients, hospital staffs and students.

All subjects were divided into two groups according to BMI. 51 subjects were non-obese $(18.5-24.9 \mathrm{~kg}$ / $\mathrm{m}^{2}$ ) and 39 were overweight $\left(25-29.9 \mathrm{~kg} / \mathrm{m}^{2}\right)$. Each group was further subdivided into female and male. The protocol of this study was approved by the Institutional Review Board (IRB) of BSMMU.

The aim and procedure of this study was explained and informed written consent was taken from the participants. Then a detailed personal, medical, family, dietary history and in female menstrual history was taken. A thorough physical examination of the subjects were done. Height and weight were taken and BMI was calculated. All information was documented in a prefixed datasheet. Then for biochemical tests, $8 \mathrm{ml}$ of venous blood was collected under aseptic precautions and ECG (MAC 4003 channel ECG machine, General Electric Company, India) was also done. All the subjects were free from diabetes, thyroid disorder, anemia, liver disease, renal and cardiovascular disease.

Before head up tilt test, the subjects were instructed to fast for 1 hour and they were requested not to drink or smoke during that time. They were asked to urinate just before the examination and the room temperature was maintained at $25^{0} \mathrm{C}$. All the subjects rested 10 minutes on the tilt table. Supine $\mathrm{HR}, \mathrm{SpO}_{2}$., SBP, DBP,MAP were recorded. Then tilting was done at $60^{\circ}$ for 10 minutes by a motorized tilt table (Hi-Lo Mode; 220 volt; Cat No: IEMR4093HL; International Elecro Medical Co, India). Data were recorded for every minute for 10 minutes after tilting. After 10 minutes the tilt table was brought back to the horizontal position. The maximum change in $\mathrm{HR}, \mathrm{SpO}_{2}, \mathrm{SBP}$ and $\mathrm{DBP}$ after tilting was considered as the cardiovascular response to tilt. The subjects were asked to avoid the movement of the lower limb during the procedure and also instructed if he/she feel any dizziness, lightheadedness or discomfort then he/ she must inform it to the operator, so that the tilting would be ceased immediately and the table would be brought back to the horizontal position. BP were recorded by an automated sphygmomanometer (HME-7120, Omron Health Care Co. Ltd., Vietnam). By pulse oximeter (YK-88 LED, Yonker, China) $\mathrm{HR}$ and $\mathrm{SpO}_{2}$ were measured.

Data were expressed as Mean \pm SD. Statistical analysis was done using SPSS version 22. Independent sample ' $t$ ' test, Pearson's correlation analysis and Chi square test were done. $p$ value of $<0.05$ was considered as statistically significant.

\section{Results}

All subjects were similar by age. The frequency of non-obese and overweight subjects were almost similar in both females and males. But BMI was different in both genders (Table I). 
Significantly lesser fall of SBP $(p<0.05)$ was noted in overweight females (Table II) whereas significantly lesser rise of HR $(p<0.05)$ was observed in males after tilting (Table III).

In addition, rise of heart rate was negatively correlated and fall of SBP was positively correlated with higher BMI in female (Table IV). In contrast, fall of $\mathrm{SpO}_{2}$ was negatively correlated with higher BMI in male (Table V). All these relationships were statistically significant $(p<0.05)$. Significant inverse relationship between rise of DBP and rise of MAP was noted with age only $(p<0.05)$. In addition, significant inverse relationship of rise of HR was found with age and gender $(\mathrm{p}<0.05)$.

The time course response of $\mathrm{HR}, \mathrm{SpO}_{2}, \mathrm{SBP}$, DBP and MAP after tilting were shown in figure 1 in an individual subject.

Table I: Age and distribution of male and female in two BMI groups $(\mathrm{N}=90)$

\begin{tabular}{lccc}
\hline Groups & $\begin{array}{c}\text { Non-obese } \\
(\mathrm{n}=51)\end{array}$ & $\begin{array}{c}\text { Overweight } \\
(\mathrm{n}=39)\end{array}$ & $\begin{array}{c}\mathrm{p} \\
\text { value }\end{array}$ \\
\hline Age(Years) & $39.14 \pm 11.88$ & $39.38 \pm 9.86$ & 0.916 \\
BMI(kg/m²) & $22.01 \pm 1.11$ & $27.49 \pm 1.31$ & $0.000^{* * *}$ \\
Female(no.\%) & $24(47.05 \%)$ & $21(53.85 \%)$ & 0.157 \\
Male(no.\%) & $27(52.94 \%)$ & $18(46.15 \%)$ & 0.157 \\
\hline
\end{tabular}

Data were expressed as mean \pm SD and no (\%). Statistical analysis were done by Independent sample ' $t$ ' test and chi square test; Non-obese: BMI 18.5-24.9 kg/m²; Overweight: BMI $25-29.9 \mathrm{~kg} / \mathrm{m}^{2} ; * * *-\mathrm{p}<0.001$.

Table II: Cardiovascular response and peripheral capillary oxygen saturation after tilting in female with different BMI group ( $\mathrm{N}=45)$

\begin{tabular}{lcc}
\hline Variables & $\begin{array}{c}\text { Non-obese } \\
(\mathrm{n}=24)\end{array}$ & $\begin{array}{c}\text { Overweight } \\
(\mathrm{n}=21)\end{array}$ \\
\hline Rise of HR (beats/min) & $11.45 \pm 4.96$ & $9.43 \pm 4.37$ \\
Fall of $\mathrm{SpO}_{2}(\%)$ & $4.7 \pm 4.4$ & $5.43 \pm 3.59$ \\
Fall of $\mathrm{SBP}(\mathrm{mm} \mathrm{Hg})$ & $7.58 \pm 4.11$ & $11.52 \pm 5.81^{*}$ \\
Rise of DBP $(\mathrm{mm} \mathrm{Hg})$ & $6.5 \pm 3.05$ & $7.67 \pm 6.08$ \\
Rise of MAP $(\mathrm{mm} \mathrm{Hg})$ & $4.74 \pm 2.73$ & $5.84 \pm 3.92$ \\
\hline
\end{tabular}

Data were expressed as Mean $\pm \mathrm{SD}$. Statistical analyses were done by Independent sample ' $t$ ' test; SBP- systolic blood pressure; DBP- diastolic blood pressure; MAP- mean arterial pressure; $\mathrm{HR}$ - heart rate; $\mathrm{SpO}_{2}$ - peripheral capillary oxygen saturation; Non-obese - BMI- $18.5-24.9 \mathrm{~kg} / \mathrm{m}^{2}$; Overweight- BMI $25-29.9 \mathrm{~kg} / \mathrm{m}^{2}$; n-number of the subjects in each groups; $\mathrm{N}$ - total number of subjects; * $-\mathrm{p}<0.05$.
Table III: Cardiovascular response and peripheral capillary oxygen saturation after tilting in male with different BMI $(\mathrm{N}=45)$

\begin{tabular}{lrc}
\hline Variables & $\begin{array}{c}\text { Non-obese } \\
(\mathrm{n}=27)\end{array}$ & $\begin{array}{c}\text { Overweight } \\
(\mathrm{n}=18)\end{array}$ \\
\hline Rise of HR (beats/min) $11.56 \pm 7.2$ & $7.22 \pm 4.65^{*}$ \\
Fall of SpO $2(\%)$ & $5.48 \pm 4.33$ & $4.61 \pm 4.49$ \\
Fall of SBP (mm Hg) & $7.29 \pm 4.86$ & $6.11 \pm 2.74$ \\
Rise of DBP (mm Hg) & $8.33 \pm 4.54$ & $8.44 \pm 3.68$ \\
Rise of MAP (mm Hg) $5.96 \pm 4.08$ & $5.59 \pm 3.35$ \\
\hline
\end{tabular}

Data were expressed as Mean \pm SD. Statistical analyses were done by Independent sample ' $t$ ' test; SBP- systolic blood pressure; DBP- diastolic blood pressure; MAP- mean arterial pressure; $\mathrm{HR}$ - heart rate; $\mathrm{SpO}_{2}$ - peripheral capillary oxygen saturation; Non-obese: BMI $18.5-24.9 \mathrm{~kg} / \mathrm{m}^{2}$; Overweight: BMI $25-29.9 \mathrm{~kg} / \mathrm{m}^{2}$; n-number of the subjects in each groups; $\mathrm{N}$ - total number of subjects; * $\mathrm{p}<0.05$.

Table IV: Correlations of rise of HR, fall of $\mathrm{SpO}_{2}$, fall of SBP, rise of DBP and rise of MAP with BMI in female $(\mathrm{N}=45)$

\begin{tabular}{lcc}
\hline Variables (Dependent) & \multicolumn{2}{c}{ BMI } \\
\cline { 2 - 3 } & r value & p value \\
\hline Rise of HR & -0.817 & $0.000^{* * *}$ \\
Fall of $\mathrm{SpO}_{2}$ & -0.078 & 0.609 \\
Fall of SBP & 0.366 & $0.013^{*}$ \\
Rise of DBP & 0.105 & 0.493 \\
Rise of MAP & 0.173 & 0.257 \\
\hline
\end{tabular}

Statistical analyses were done by Pearson's correlation test; SBP- systolic blood pressure; DBP- diastolic blood pressure; MAP- mean arterial pressure; $\mathrm{HR}$ - heart rate; $\mathrm{SpO}_{2}$ - peripheral capillary oxygen saturation; $\mathrm{N}$ - total number of subjects; * $\mathrm{p}<0.05 ; * * *-\mathrm{p}<0.001$

Table V: Correlations of rise of $\mathrm{HR}$, fall of $\mathrm{SpO}_{2}$, fall of SBP, rise of DBP and rise of MAP with $\mathrm{BMI}$ in male $(\mathrm{N}=45)$

\begin{tabular}{lcc}
\hline Variables & \multicolumn{2}{c}{ BMI } \\
\cline { 2 - 3 } & r value & p value \\
\hline Rise of HR & 0.117 & 0.444 \\
Fall of $\mathrm{SpO}_{2}$ & -0.432 & $0.003^{* *}$ \\
Fall of SBP & -0.168 & 0.271 \\
Rise of DBP & 0.045 & 0.768 \\
Rise of MAP & 0.062 & 0.684 \\
\hline
\end{tabular}

Statistical analyses were done by Pearson's correlation test; SBP- systolic blood pressure; DBP- diastolic blood pressure; MAP- mean arterial pressure; $\mathrm{HR}$ - heart rate; $\mathrm{SpO}_{2}$ peripheral capillary oxygen saturation; $\mathrm{N}$ - total number of subjects; ** - $p<0.01$.

Volume 15 No. 1 June 2020: 6-10 


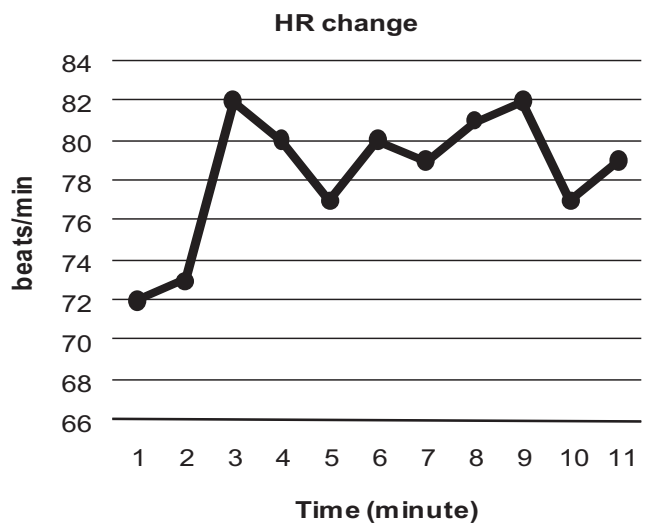

(a)

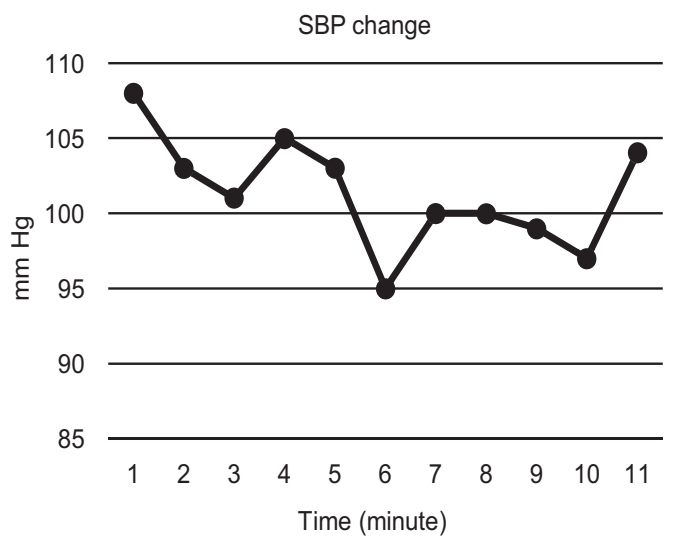

(c)

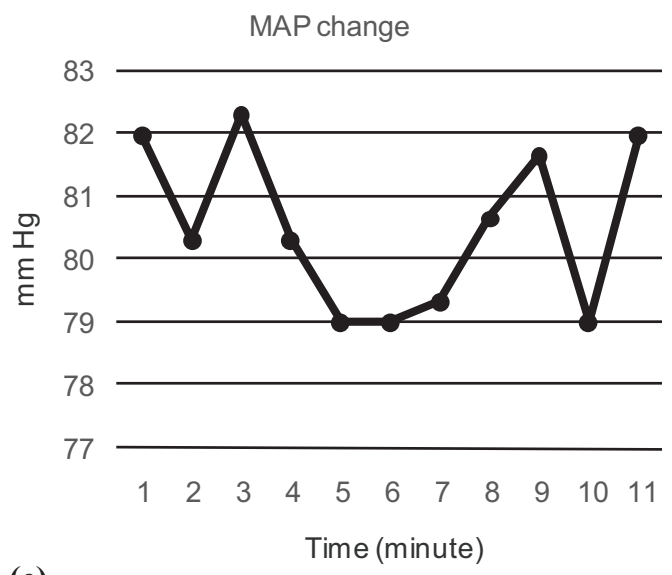

(e)

Figure $1(\mathbf{a}, \mathbf{b}, \mathbf{c}, \mathbf{d}, \mathbf{e})$ : Time course change in $\mathrm{HR}, \mathrm{SpO}_{2}$, SBP, DBP and MAP after tilting was shown in an individual subject. Baseline value before tilting was shown at 1 minute.

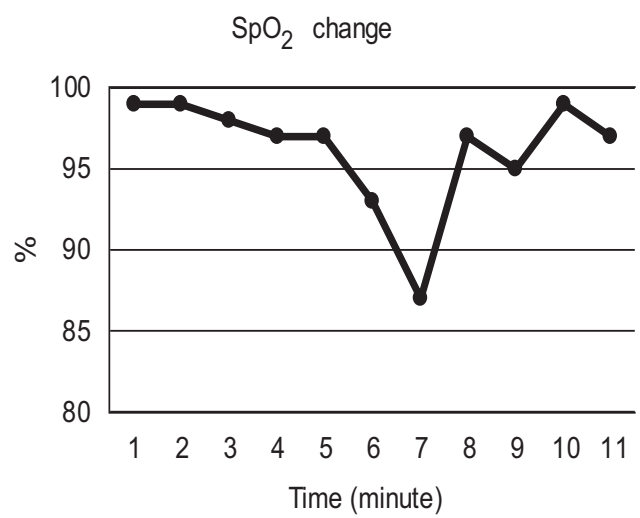

(b)

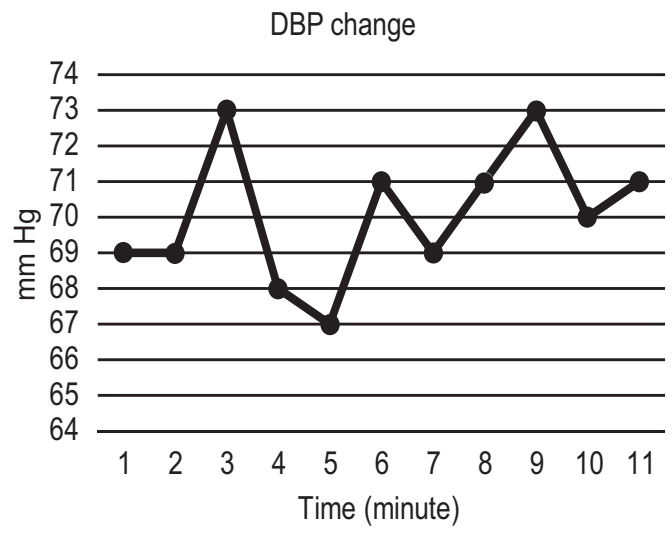

(d)

\section{Discussion}

In our study, tilt response of all parameters were compared between subjects with normal and overweight BMI in both sexes to observe the effect of higher BMI (overweight) on the cardiovascular response to postural stress in otherwise healthy subjects. We found a greater fall of SBP in overweight females and lesser rise of HR in overweight males which indicated that overweight significantly affects cardiovascular adjustment to posture in both females and males. It is further supported by significant correlation of HR and BP with BMI in female in this study.

This observation suggests that not only obesity even overweight may have a significant influence on cardiovascular adjustment to orthostatic stress. $^{5}$ 
Our study also demonstrated that overweight females were more prone to weaker cardiovascular response suggesting relationship of gender and BMI with cardiovascular response to tilting.

The observation of this study is analogous with Akther et al. They observed less sympathetic activity with increase body fat percentage. ${ }^{8}$ Increased pulse rate in obese person was observed by Grassi et al., whereas others did not found any significant change in HR response to tilt between obese and non-obese. ${ }^{9}$

It has been suggested that BMI had significant influence on the potency of cardiovascular adjustment to postural stress. Obesity affects this cardiovascular homeostasis largely by affecting the autonomic regulation of circulatory function. Obesity is usually associated with the sympathetic and parasympathetic imbalance and reduced baroreceptor sensitivity (BRS) ultimately causing poor compensatory adjustment of HR and BP in an upright posture. ${ }^{5}$ According to the suggestions of different investigators, the reduced sympathetic nerve activity is due to defect in the sympathetic nerve activation and peripheral adrenoreceptors. ${ }^{10,5-6}$. They also revealed impaired baroreceptor function in normotensive obese.

The exact mechanism involved in increased adiposity and autonomic dysregulation is yet uncertain but chronic hyperinsulinemia associated with obesity may have a direct effect on the hypothalamus causing sympathetic overactivity, parasympathetic withdrawal and impaired baroreceptor function ${ }^{11}$.

In the present study, we recruited overweight but not obese person. The results in the overweight person in our study showed a lack of sign of vagal withdrawal and sympathetic over-activity which is true for obesity. Therefore, the effect of BMI below the level of obesity on attenuated circulatory adjustment is still to be investigated.

\section{Conclusion}

Based on the results of the study it can be concluded that overweight subjects of both gender are prone to weak circulatory adjustment to the postural challenge.

\section{References}

1. Stapleton PA, James ME, Goodwill AG, Frisbee JC. Obesity and vascular dysfunction. Pathophysiology 2008; 15(2):79-89.

2. WHO Obesity. Geneva, World Health Organization, 2019. [Internet] [cited 2019 Jul 29]. Available from: https://www.who.int/topics/obesity/en/.

3. National Heart, Lung, Blood Institute, National Institute of Diabetes, Digestive, Kidney Diseases (US). Clinical guidelines on the identification, evaluation, and treatment of overweight and obesity in adults: the evidence report. National Heart, Lung, and Blood Institute; 1998. [Internet] [cited 2019 Aug 21] Available from: https://www.ncbi.nlm.nih.gov/books/ NBK2003/

4. Weisell RC. Body mass index as an indicator of obesity. Asia Pac J Clin Nutr 2002; S681-

5. Zahorska-Markiewicz B, Mizia-Stec K, JastrzebskaMaj E, Mandecki T, Bilewicz-Wyrozumska T, Mucha Z, Gasior Z. Tilt table testing in obesity. Int J Cardiol $2003 ; 88(1): 43-8$.

6. Akhter S, Begum N, Ferdousi S, Begum S, Ali T. Sympathetic nerve function status in obesity. $\mathrm{J}$ Bangladesh Soc Physiol 2010; 5(1):34-9.

7. McKeigue PM, Shah B, Marmot MG. Relation of central obesity and insulin resistance with high diabetes prevalence and cardiovascular risk in South Asians. The Lancet 1991; 337 (8738): 382-6.

8. Alvarez GE, Beske SD, Ballard TP, Davy KP. Sympathetic neural activation in visceral obesity. Circulation 2002; 106 (20): 2533-6.

9. Grassi G, Seravalle G, Cattaneo BM, Bolla GB, Lanfranchi A, Colombo M, Giannattasio C, Brunani A, Cavagnini F, Mancia G. Sympathetic activation in obese normotensive subjects. Hypertension 1995; 25(4): 560-3.

10. Spraul M, Ravussin E, Fontvieille AM, Rising R, Larson DE, Anderson EA. Reduced sympathetic nervous activity. A potential mechanism predisposing to body weight gain. J Clin Invest 1993; 92(4):17305 .

11. Skrapari I, Tentolouris N, Perrea D, Bakoyiannis C, Papazafiropoulou A, Katsilambros N. Baroreflex sensitivity in obesity: relationship with cardiac autonomic nervous system activity. Obesity 2007; 15(7):1685-93

Volume 15 No. 1 June 2020: 6-10 